www.terciocreciente.com

http://revistaselectronicas.ujaen.es/index.php/RTC

Ensayo

\section{Edición de un livre d'artiste. Compartir nuevos espacios Edition of a livre d'artiste. Share new spaces}

\section{Enrique Ferré Ferri} Universitat Politècnica de València, España.

ferre2392@gmail.com

Recibido 10/02/2017 Aceptado 07/04/2017
Revisado 05/03/2017

Publicado 01/07/2017

\section{Resumen}

En este documento se trata de exponer los elementos y circunstancias que concier- ne a la edición de un Libro de Artista, como obra que es de Arte contemporáneo, centrando los comentarios a lo que concierne a la producción de la obra, al igual que se intenta abordar las fases relativas a la difusión y una posible comercialización del trabajo.
Abstract

This article tries to expose the elements and circumstances that concern the edition of an Artist Book, as a work that is of contemporary Art, focusing the comments on what concerns the production of the work. It is also intended to address the phases related to the dissemination and possible commercialization of work.

Para citar este artículo

Ferré Ferri, E. (2017). Edición de un livre d'artiste. Compartir nuevos espacios. Tercio Creciente 13, págs. 133142. https://dx.doi.org/10.17561/rtc.mextra1.8 
Revista de Estudios en Sociedad, Artes y Gestión Cultural

www.terciocreciente.com

http://revistaselectronicas.ujaen.es/index.php/RTC
Monográfico Extraordinario I Julio 2017

Ensayo
ISSN: 2340-9096

DOI: $10.17561 /$ rtc.mextra1.8

Palabras clave / Keywords

Libro de artista, Nuevos espacios, Arte Contemporáneo, Edición / Artist book, Contemporary art, New spaces, Edition, Publication

Para citar este artículo

Ferré Ferri, E. (2017). Edición de un livre d'artiste. Compartir nuevos espacios. Tercio Creciente 13, págs. 133142. https://dx.doi.org/10.17561/rtc.mextra1.8 


\section{Introducción}

En el proceso de creación de una obra, el autor, puede estar condicionado por una idea, una referencia, o un encargo. Para llevar a cabo y materializar el proyecto, siempre hay que establecer una estrategia previa respecto a la producción de la pro- puesta; en la referida fase, el artista está habituado a su proceso, pues en dicha mecánica se ha ido formando y conviviendo en los pasos que tiene que dar en la creación y la ejecución de sus obras. En el autor siempre prima, previamente, el acto de creación sobre el resto de fases que siguen al mismo, como son el desarrollo y la evolución de la propuesta. Tan pronto tiene concretada y clara su idea, surge el im- pulso productivo, y para empezar a actuar es preciso establecer una estrategia, un plan de trabajo, de como llevar a cabo la materialización del proyecto; hay que deci- dir los medios a utilizar, su empleo y tener en cuenta todo lo que concierne a dicho proceso, intentando obtener el mejor resultado posible en la plasmación de la obra y la máxima efectividad en la labor.

Pero el artista no se limita a la labor de un artesano que realiza un trabajo y no se preocupa del destino final de la obra, para el artista la evolución de su proyecto no finaliza con la fase de producción, sino también tiene que valorar las estrategias a establecer para que la obra sea expuesta y mostrada a los ojos del espectador, es- tudiar las posibilidades que existen para difundir el resultado del esfuerzo realizado, tanto si es una obra única o una edición, como el caso de los Libros de Artista. Habitualmente, llegado a este punto, el artista suele dar por finalizado todos los procesos que giran entorno a su obra, pero existe una continuidad a la qué no suele estar tan familiarizado, la comercialización del resultado de su proyecto. En tal circunstancia, el artista, debe superar y cubrir dicha fase, si desea vivir de su obra, deberá apren- der a moverse en los cauces mercantilistas y sus connotaciones burocráticas y fisca- les, siempre que desee obtener fruto económico de su trabajo.

\section{Edición de un livre d'artiste}

En este documento se trata de exponer los elementos y circunstancias que concierne a la edición de un Libro de Artista, como obra que es de Arte contemporáneo, centrando los comentarios a lo que concierne a la producción de la obra, al igual que se intenta abordar las fases relativas a la difusión y una posible comercialización del trabajo.

En la edición de un Libro de Artista la implicación del autor es máxima, en todas las fases, desde la creación a la materialización 
de la edición, y total, muy especialmen- te, en el caso del Livre d'Artiste. Desde el primer momento, incluso en el caso de que no exista un encargo o condicionamiento concreto de la obra, el artista ha de pensar, inicialmente, en todo lo que precisa para la realización de su proyecto, sin olvidarse de que el mismo puede tener una difusión más o menos amplia y, llegado el caso, una posible comercialización; tal conocimiento es preciso tenerlo a fin de disponer del material suficiente para llevar a cabo la edición y permitirle una mejor planifica- ción del trabajo; en el caso de un encargo concreto las condiciones difieren un poco. La referida fase inicial del proceso puede ser un poco más compleja, cuando en la intervención de la obra intervienen otros artistas o se depende de otros colaborado- res, pues hay que establecer los procedimientos necesarios para coordinar la intervención de los participantes en las diferentes partes del proyecto.

Para la planificación del trabajo, en el caso de un Libro de Artista, se ha de tener en cuenta los siguientes puntos:

- De cuantos ejemplares ha de constar la edición de la obra. Puede ser una obra única, una edición numerada, una edición sin numerar, una edición sin términos de prohibición en su reproducción, etc.

- Posibles lectores/espectadores que pueden tener acceso a la edición y quienes pueden ser los destinatarios finales del libro. La obra puede estar dirigida: a lecto- res infantiles, a personas adultas, la posibilidad de que sean lectores invidentes, etc.

- Formato del libro, tipo de soporte, número de páginas u hojas. Tipo de encuader- nación, estilo de cosido que puede ser visto o no, hilos a utilizar. Si el soporte va a ser papel (lo más habitual), gramaje del mismo, calidad, comprobar dirección de las fibras y aprovechar el papel sin problemas, convenencia de posibles plegados, troquelados. Éste es un apartado que requiere bastante atención, tanto por la varie- dad de términos a tener en cuenta como, las decisiones que se tomen, todas ellas van a determinar el proceso de la realización de la edición.

- Decidir si la obra va a contener imagen, que técnicas se van a emplear y como se van a realizar sus impresiones. Si, además de las imágenes, hay que incluir texto, personal o no; si las palabras van a ser impresas o no. En caso de impresión, contar la posibilidad realizar registros con tipos móviles, y en su caso, el cuerpo de los mismos, la familia tipográfica a emplear, con cuantas tintas, etc. También este apartado tiene gran importancia y requiere gran atención, además de la presencia del artista, al igual que el mismo disponga de conocimientos de tipografía si se emplea maquinaria tipográfica, toda vez que según las dificultades que puedan surgir, tendrá capacidad para optar por una mejor solución y proseguir avanzando en el proceso de la edición. 
Las citadas puntualizaciones son cuatro puntos muy importantes, además de otros más a tener en cuenta pero considerados más secundarios. Los dos primeros puntos son genéricos para todas las obras, los dos últimos son más concretos y determinados para cada trabajo y, en los mismos, se requiere una mayor implicación del autor o autores.

Quizás, para que esta parte referida a las estrategias de la producción en la edición de un Libro de Artista quede un poco más clara, vamos a exponer el proceso llevado a cabo en la realización de un Libro de Artista colectivo, con la intervención de varios artistas como editores y realizadores de la obra. En el caso de trabajar en grupo, para una misma obra, se requiere bastante más coordinación, como se ha apuntado, que para el caso de un libro individual.

El ejemplo que se expone es la realización de un Livre d'Artiste titulado, Con muchos caracteres, trabajo propuesto y aceptado para la participación en el Memorial Emilio Sdun. Es un Livre d'Artiste, un Libro de Artista colectivo, la primera obra de estas características que ha sido editada en el Museo de la Imprenta de El Puig de Santa María, en Valencia, museo considerado como el segundo de Europa en importancia, por sus características, después del museo de Maguncia, Alemania.

Para llevar a cabo el proyecto, se constituyó un grupo colectivo de artistas, dentro de la asociación L'Horta Gràfica, asociación de alumnos y ex-alumnos de la Facultad de Bellas Artes de la UPV, de Valencia. En principio, iban a participar unas doce personas, todas ellas con conocimientos del empleo de tipos móviles de tipografía y de Libro de Artista. El libro se iba a imprimir, en verano, en los talleres del Museo de la Imprenta de El Puig de Santa María, por lo que el horario de trabajo debía estar condicionado al horario establecido para el museo, de martes a domingo, desde las diez horas de la mañana a las catorce horas de la tarde; por las tardes, excepto festivos, desde las dieciséis horas hasta las dieciocho horas, para evitar cualquier alteración en el horario del personal y del funcionamiento de la institución. Debido a diferentes circunstancias personales, al final, el grupo quedó reducido a ocho personas.

En cuanto al contenido del Livre d'Artiste se pensó que, el protagonista del mismo, debía ser la tipografía, los tipos móviles disponibles en el Museo, toda vez que el Libro de Artista es el espacio donde la letra, la tipografía, la imagen, el silencio, de forma individual o conjunta, se hace poesía o, como apuntaba El Lisitski, la tipografía permite realizar una composición estallada. La obra, aunque iba a ser una muestra de los tipos existentes en el museo con interpretación personal en la composición, no iba a tener la consideración de un catálogo. El formato de la obra elegido fue el de un libro encuadernado con tapas de cartón, cosido visto, y de hojas agrupadas en 
cuadernillos y plegadas en tamaño de A 5. La impresión de la tipografía se iba a realizar en el Museo de la Imprenta, aunque al no tener posibilidades económicas y tiempo suficiente para adecuar las máquinas expuestas, iba a ser manual, para ello se disponía de un saca pruebas y un tórculo; no obstante, para la preparación de los textos, se pautó seguir los pasos empleados en toda composición tipográfica como el empleo de ramas, imposiciones, espacios en blanco, medir con regla de cíceros. El entintado se realizaría de forma manual, con rodillos, y empleo de tintas grasas.

Las referidas pautas genéricas fueron expuestas y presentadas para que fueran aceptadas en el citado Memorial Emilio Sdun. Una vez recibida la aprobación se siguió avanzando en la preparación de las estrategias a aplicar en el desarrollo de la producción de la obra, y para ello se estableció una continua comunicación entre todos los participantes vía mail, al estar cada uno ocupado en diferentes tareas y espacios, y más en un periodo de tiempo muy estresante para los estudiantes, por ser periodo de finalización del curso universitario e inicio del periodo vacacional. El método de comunicación empleado ha resultado muy eficiente, en especial en la última fase de impresión, por coincidir más personas de las que en un principio se había planteado en una misma franja horaria, ello evitó interferencias y que el trabajo se ha podido realizar de forma

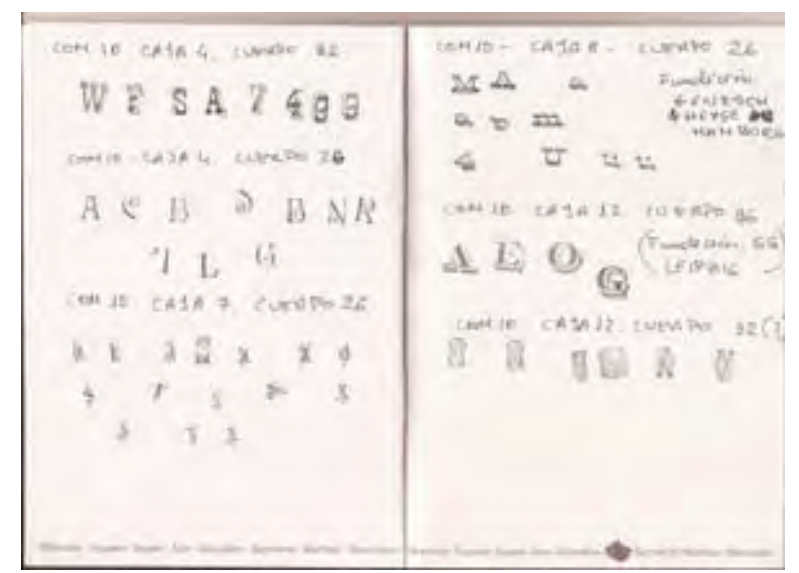

Fig. 1 Registro de algunas letras

ordenada y muy profesional, no causando ningún trastorno al funcionamiento del museo, requisito imprescindible a cumplir desde un principio.

El número de libros que se decidió producir para la edición era de un número determinado de ejemplares, el número de libros requeridos para la tirada según las normas del Memorial, un libro para cada uno de los participantes y un ejemplar para el Museo de la Imprenta. La edición final iba a constar de quince ejemplares, numerados y firmados por los artistas participantes en el colofón del libro. Los autores participantes iban a tener a su disposición, para sus 
Revista de Estudios en Sociedad, Artes y Gestión Cultural

www.terciocreciente.com http://revistaselectronicas.ujaen.es/index.php/RTC
Ensayo impresiones, hojas de formato A 4 que se doblarán para formar cuadernillos de formato A 5. En este punto, ha habido la decisión, por parte de algunos artistas, de utilizar hojas de formato A 4 dobles, aun- que el formato final plegado iba a ser A 5. El papel elegido fue de color blanco y gramaje de 160 gr.

Como se ha citado previamente, el contenido de la obra es el registro de diferentes tipos móviles existentes en el museo, siendo cada artista responsable de la edición de su cuadernillo, aunque compartiendo las opiniones y sugerencias del resto de compañeros. Para saber que tipografías se iban a utilizar, antes de empezar la edición, se ha procedido a la catalogación de las diferentes familias de letras tipográficas de cuerpo igual y superior a 24 puntos, a dos cíceros, para de este modo tener mayor facilidad en el montaje de las composiciones, debido a la limitación de los equipos de impresión disponibles.

Otro motivo por acotar el tamaño de cuerpo estaba pensado en evitar problemas en el momento del entintado, al ser manual, por posibles obturaciones del ojo de los tipos y perder calidad en la impresión tipográfica. Para la indicada catalogación se ha realizado un registro manual de los caracteres y ordenado, la impresión de las letras, por similitud de características. Al no existir una indicación clara en las cajas del tamaño de los cuerpos, se ha tenido que recurrir a la regla de cíceros, para comprobar y confirmar la medida correspondiente de cada familia tipográfica. En el proceso de catalogación, se encontraron letras muy diferentes a las que

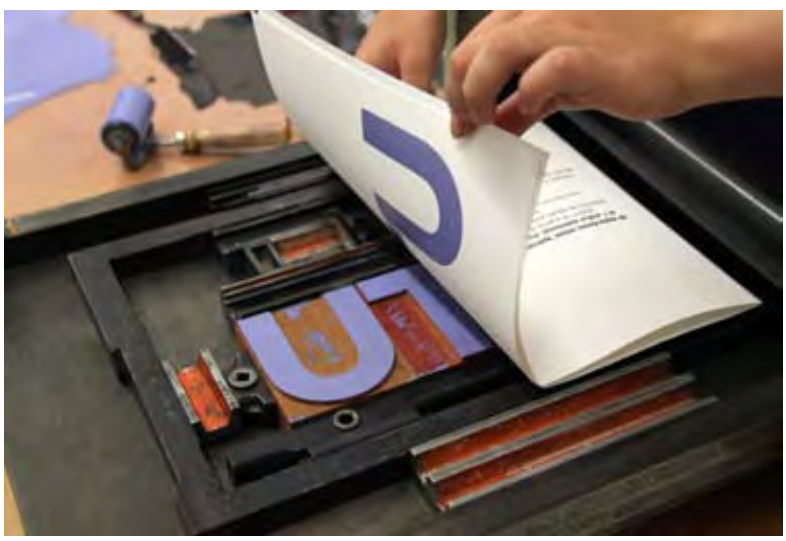

Fig. 2 Impresión en saca pruebas

disponemos en nuestra Facultad de BB.AA. y, con ello, podemos constatar la gran variedad de tipografías que existían y se empleaban en las imprentas valencianas, con una abundancia de letras de cuerpo inferior a 24 puntos y cierta limitación en tamaños superiores a dos cíceros, habitualmente destinados para la impresión de titulares. Tal circunstancia nos anima a invitar que, estudiantes y amantes de la Tipografía, puedan realizar es- tudios de investigación y trabajos de posgrado en el Museo de la Imprenta, hay bas- tante material disponible, incluso maquinaria, para poder proceder a un estudio profundo del mismo. Consideramos de gran interés dar a la luz un rico patrimonio, no solo para la Comunidad Valenciana, sino también para todos; el interés por el mismo, lo hemos podido comprobar durante nuestra estancia en dicho espacio, observando 
que la procedencia de las personas, en las visitas realizadas, eran en gran parte turistas nacionales y extranjeros.

De antemano, conociendo los medios de impresión a emplear, éramos conscientes de que la calidad de los registros no iba a ser perfecta, comparada con la ejecutada con prensas con rama vertical y entintado automático, pero dentro de las posibles imperfecciones y errores, como artistas,

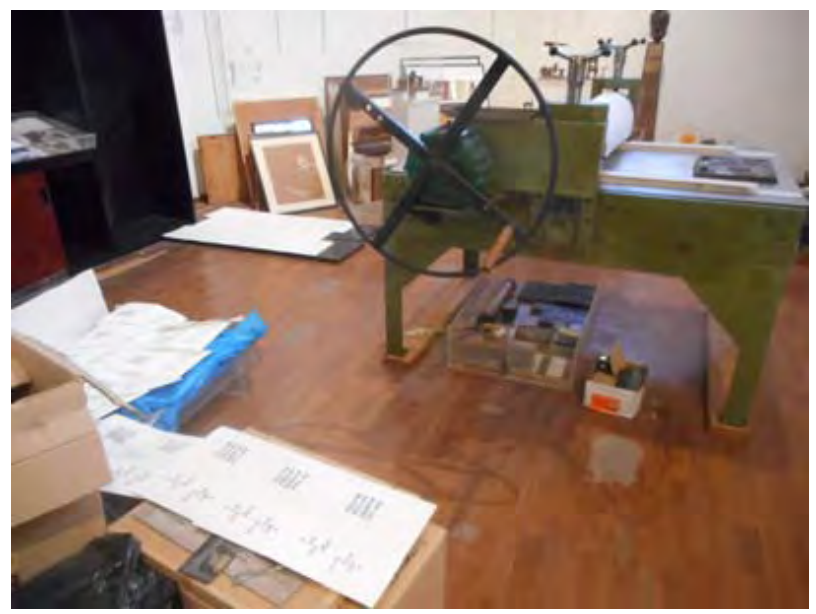

Fig. 3 Impresión en tórculo sabíamos que podríamos encontrar valores plásticos no predeterminados, el azar iba a ser un compañero de camino, circunstancia que compartía con una de las directrices del trabajo, DaDa. Cuando se reali- zan impresiones manuales en horizontal, los entintados con rodillo no son uniformes, la colocación y retirada de papel está sujeta a posibles oscilaciones o movimientos inadecuados, ello provoca que se registren huellas no deseadas, como letras movi- das que generan mucho ruido, o por presiones con cama de papel no uniforme para todos los tipos, especialmente cuando se emplean caracteres de madera. Pero como se ha comentado, siempre se analizará el resultado y se intenta estudiar si son efectos a considerar y presentar.

El espacio de trabajo empleado, aunque no es el ideal, nos hemos acomodado a sus limitaciones. En el tiempo que se ha permanecido en el mismo, casi tres meses, se han producido situaciones muy similares a la actividad en otros talleres de impresión. El colectivo ha trabajado, inicialmente, de forma casi individual y cómoda, sin estar sujeto a presiones, pero el último mes, los últimos quince días, el número de participantes se ha concentrado y ello ha obligado a crear turnos para imprimir, con programación muy variable, debido a diferentes circunstancias 
personales, y como se ha comentado anteriormente, ha obligado a estar en continuo contacto entre los par- ticipantes para evitar solapes y tiempos muertos. Tal situación recuerda un poco, a nivel universitario, a las fechas de entrega de trabajos finales; a nivel industrial, las prisas existentes de última hora, en la entrega de encargos. Pero todo ello es superable cuando existe, responsabilidad y armonía, dentro del equipo y así lo han demostrado todos con la ilusión de embarcarnos en nuevos proyectos.

Otro factor que jugaba en contra, con respecto a un proyecto normal y a los que es tamos habituados, era que el espacio de trabajo no está pensado y diseñado como taller de imprenta, ello suponía que hubo que improvisar espacios para el secado de las impresiones, realizar largos desplazamientos para aprovisionarse de elementos accesorios para las composiciones, como regletas, cuadradillos, a pesar que la exactitud extrema no era precisa al trabajar con la rama en horizontal.

Cubierta la fase de impresión, se pasó a la de plegado de las hojas y componer los cuadernillos correspondientes, para después ajustarlos con la guillotina y dejarlos a la medida del formato deseado, dejando el material preparado para realizar el proceso de encuadernación, su cosido a mano, e inclusión de las páginas de título, colofón y cortesía. El cosido se ha realizado con telar, para ajustar mejor los nervios, aunque con libros del tamaño editado, tampoco es un elemento imprescindible. Las tapas se han encolado a continuación.

Si por parte de los artista se ha tenido muy claro todo lo concerniente al proceso de producción y edición de la obra, el cual espero haber plasmado de forma clara al lector de este documento, también se tenía claro cual iba a ser la difusión de la obra en esta ocasión, se va a dar a conocer de forma amplia a través del Memorial. Por una parte, el ejemplar destinado al Memorial Emilio Sdun, su organización se va a encargar de difundirlo, al igual que al resto de las obras que participan en el mismo. Por otra parte, al ser una obra realizada por asociados de L'Horta Gràfica, se va a contar con dicha plataforma para poder mostrar la obra en los diferentes eventos en que se participe, como son las ferias de Libros de Artista a nivel nacional e internacional, además de la divulgación de imágenes de la obra, a través de fotografías y vídeo, en las plataformas de la red, Facebook y Web, por parte de L' Horta Gràfica. Otro punto más de difusión a incluir, va a ser el Museo de la Imprenta de El Puig de Santa María, un ejemplar quedará depositado en el museo. Incluso se tiene la idea de programar una 
exposición entorno al Libro de Artista impreso, creemos que es una muy buena oportunidad, para la institución, de poder mostrar a los visitantes del registro de parte de la tipografía existente en los chebalieres y que posibilidades de expresión existen con la misma, al igual que animar, después de la experiencia adquirida, a realizar nuevos proyectos y eventos en dicho lugar.

Si se ha intentado exponer, de forma amplia, los pasos que requeridos para la edición de un Libro de Artista como, de forma breve, la parte correspondiente a la difusión de una obra concreta, nos queda pendiente comentar la parte referida a la comercialización de la misma. En principio, porque la edición realizada no está prevista comercializarla por parte de los artistas de forma directa y, en segundo término, es un mercantilismo al cual, los artistas participantes, no estamos tan habituados ni incidimos de forma muy plena.

\section{Conclusión}

Como conclusión, después de una nueva experiencia en la edición de un Livre d'Artiste colectivo, se puede confirmar que

- En el proceso de ejecución de la obra, los artistas se van acoplando a los medios disponibles y a las circunstancias del momento, tomando decisiones y realizando modificaciones que no estaban contempladas en un inicio, ello indica la importancia de la presencia del artista en la ejecución de trabajos de tales características, permite poder decidir de forma inmediata, y no detener el proceso de realización, algo muy importante cuando se trabaja en equipo o en una cadena. La primera parte es considerada, en nuestra opinión, como la más enriquecedora y de la que habitualmente disfrutan los artistas, y así nos lo han confirmado los compañeros que han participado en la propuesta.

- Otro paso importante es la difusión de la obra, en este punto son fundamentales los cauces disponibles y empleados para dar a conocer el libro una vez finalizado; es conveniente elegir los medios y espacios de difusión para que el trabajo pueda ser valorado como tal, la obra tiene que someterse al juicio y comentario del espectador, si no es así quedará depositado en un olvido, no será reconocida como tal mientras no se muestre y reciba la aceptación de los verdaderos destinatarios de la obra de arte. Hay eventos, unos más importantes que otros, como plataformas para mostrar la edición y darle cierta difusión, al igual que, en dichos lugares, los artistas tienen posibilidad de participar personalmente y darse a conocer como artis- tas o ampliar contactos. No obstante, la comercialización es el punto que se escapa en muchas ocasiones al control del artista, el cuál insistirá, más o menos, en el referido mercantilismo, en función de sus necesidades personales. El artista, independiente de las recompensas económicas y premios, desea el reconocimiento de su obra, ello es posible alcanzarlo a través de la difusión de la misma de manera amplia, exponiendo su trabajo, divulgando sus imágenes o publicando artículos de su trabajo; tales circunstancias pueden ser posibles en el presente evento del Memorial Emilio Sdun, como el presente escrito de colaboración que hemos redactado para el mismo. 